\title{
Crank-Nicolson Type Method for Burgers Equation
}

\author{
Sachin S. Wani and Sarita H. Thakar
}

\begin{abstract}
In this paper we presented Crank-Nicolson type scheme for numerical solution of one dimensional non linear Burgers equation with Homogeneous Dirichelets Boundary conditions. The difference scheme is shown to be consistent and is of second order in time and space. The numerical solutions are obtained for two test problems for different values of $t$ and constant of diffusivity $k$. The solutions are compared with existing methods.
\end{abstract}

Index Terms-Absolute error, burgers equation, convergence, Crank-Nicolson.

\section{INTRODUCTION}

First order non linear partial differential equations (PDE's) model non linear waves and arise in gas dynamics, water waves, elastodynamics, chemical reactions, transport of pollutants flood and ecological systems. Historically comparatively little was known about the extraordinary range of behavior exhibited by the solutions of nonlinear PDE's . Burgers equation is natural first step towards developing methods for control of flows. It has a large variety of applications in modeling of water in unsaturated oil, dynamics of soil in water, statics of flow problems, mixing and turbulent diffusion, cosmology and seismology.

The one dimensional non linear Burgers equation was first introduced by Beteman [1] who found its steady solutions descriptive of certain viscous flows. It was later proposed by Burger [2] as one of a class of equation describing mathematical models of turbulence. In the context of gas dynamics it was discussed by Hopf [3] and Cole [4]. In recent years many researchers have used various numerical methods specially based on finite difference, finite element boundary element techniques and direct variational method to solve Burgers equation [5]-[21]. E. Benton and Platzman [22] surveyed exact solution of one dimensional Burgers equation. In 1997 D.S. Zhang, G. W. Wei and D. J. Kouri [23] solved it for high Reynolds number, this simple approach can provide very high accuracy while using a small number of grid points. In 2005 A. Gorguis gives comparison between Cole Hopf transformation and Decomposition method for solving Burgers equation [24]. In 2006 Jerome I.V. Lewandowski [25] used Marker method which relies on the definition of convective field associated with the underlying PDE, the information about the approximate solution is associated with the response of convective field. In 2006 K. Altiparmak [26] gave Economized Rational approximation method using Pade's approximation which is efficient than Rational

Manuscript received March 31, 2013; revised May 31, 2013.

Sachin S. Wani is with the Department of Applied Mathematics Pillai's Institute of Information Technology New panvel Navi Mumbai, India (e-mail: sachin.swani@gmail.com).

Sarita H. Thakar is with the Department of Mathematics, Shivaji University Kolhapur, India (e-mail: saritakolhapur@gmail.com). approximation. In 2006 M.K.Kadalbajoo and A. Awasti [27] developed stable numerical method based on Crank Nicolson to solve Burgers equation. In $2009 \mathrm{~J}$. Biazar and $\mathrm{H}$. Aminikhah [28] solve Burgers equation by using variational iteration method by which approximate solution can be found and which is better than ADM [29]. In 2008 J. K. Djoko [30] examine the stability of a finite difference approximation for Burgers equation by approximating the nonlinear term by a linear expression using techniques based on the boundaries of the solution sequence with respect to $\Delta t$ for $t \in(0, \infty)$ and with the help of discrete Aronwall lemma stability is achieved. In 2009 Sachin S. Wani and Sarita Thakar analysed stability of Mixed Euler Method for one dimensional non linear Burgers equation. In 2009 K. Pandey and L Verma and A. K. Verma [31] wrote on difference scheme for Burgers Eqaution. In 2011 Kanti Pandey and Lajja Verma gave a note on Crank Nicolson scheme for Burgers Equation without Hopf Cole transformation solutions are obtained by ignoring nonlinear term. Crank Nicolson method is an implicit finite difference scheme to solve PDE's numerically.

In this paper we present a new difference scheme called Crank-Nicolson type scheme. The scheme is obtained by discretizing $u_{t}=k u_{x x}$ like Crank-Nicolson scheme where as discretization of $u u_{x}$ is obtained by average central difference at $t=t_{n}$ and $t=t_{n+1}$ so that the scheme remains linear at $t=t_{n+1}$. The method is shown to be second order in time and space and consistent. The solutions of Burgers equation obtained by Crank-Nicolson type method are compared with numerical solutions obtained in [9], [27], [31].

The paper is arranged as follows. In Section II exact solutions of Burgers Equation for different initial conditions are given. In Section III the difference scheme is developed the method is proved to be consistent and the scheme is of second order in both space and time. In Section IV the numerical solutions of certain test problems are obtained by Crank-Nicolson type method and results are compared with analytical solutions and other numerical methods given in [9], [27], [31].

\section{EXACT SOLUTION OF BURGERS EQUATION}

Consider one dimensional non linear Burgers equation with homogeneous Dirichlets boundary conditions.

$$
\begin{array}{cc}
u_{t}+u u_{x}=k u_{x x} & 0<x<1 \\
u(x, 0)=u_{0}, u(0, t)=u(1, t)=0 . & t>0
\end{array}
$$

where $k$ is a constant of diffusivity.

The exact solution of equation (1) is

$$
u(x, t)=2 \pi k \frac{\sum_{n=1}^{\infty} a_{n} e^{-n^{2} \pi^{2} k t} n \sin (n \pi x)}{a_{0}+\sum_{n=1}^{\infty} a_{n} e^{-n^{2} \pi^{2} k t} \cos (n \pi x)}
$$


where the Fourier coefficients $a_{n}, n=0,1,2$---are obtain from initial condition [4]

1) With the initial condition $u(x, 0)=\sin \pi x, 0<x<1$

$$
\begin{gathered}
a_{0}=\int_{0}^{1} e^{\left[-(2 \pi k)^{-1}(1-\cos \pi x)\right]} d x \\
a_{n}=2 \int_{0}^{1} e^{\left[-(2 \pi k)^{-1}(1-\cos \pi x)\right]} \cos n \pi x d x \\
n=1, \quad 2, \quad 3---
\end{gathered}
$$

2) With the initial condition $u(x, 0)=4 x(x-1)$, $0<x<1$

$$
\begin{gathered}
a_{0}=\int_{0}^{1} e^{-\frac{x^{2}}{3 k}(3-2 x)} d x \\
a_{n}=2 \int_{0}^{1} e^{-\frac{x^{2}}{3 k}(3-2 x)} \cos n \pi x d x \\
n=1, \quad 2, \quad 3---
\end{gathered}
$$

\section{CRANK-Nicolson TyPe Method}

For discretization we use the following notation

$t_{n}=t_{0}+n \Delta t, \Delta t$ is step size in $t, x_{j}=x_{0}+j \Delta x$ $0<j<N, N \Delta x=1$. The numerical solution at $t=$ $t_{n}$ and $x=x_{j}$ is denoted by $u_{j}^{n}$. The solutions at $t=t_{n}$ for $0<j<N$ are denoted by $u^{n}=\left(u_{0}^{n}, u_{1}^{n}---u_{x}^{n}\right)^{T}$.

Approximate $u_{t}$ by forward difference, $\mathrm{u} u_{x}$ by central difference at $t=t_{n}$ and $t=t_{n+1}$ so that the scheme will remain linear in $\mathrm{u}$ at $t=t_{n+1}$ and $k u_{x x}$ is approximated by usual Crank-Nicolson expression. Then discretization of equation (2.1) gives

$$
\begin{gathered}
\frac{u_{j}^{n+1}-u_{j}^{n}}{\Delta t}+\frac{1}{4 \Delta x}\left[u_{j}^{n}\left(u_{j+1}^{n+1}-u_{j-1}^{n+1}\right)+u_{j}^{n+1}\left(u_{j+1}^{n}-u_{j-1}^{n}\right)\right] \\
=\frac{k}{2(\Delta x)^{2}}\left(u_{j+1}^{n+1}-2 u_{j}^{n+1}+u_{j-1}^{n+1}+u_{j+1}^{n}-2 u_{j}^{n}+u_{j-1}^{n}\right)
\end{gathered}
$$

$$
\begin{aligned}
& \text { Define } p=\frac{\Delta t}{4 \Delta x} \text { and } r=\frac{k \Delta t}{2(\Delta x)^{2}} \\
& \qquad \begin{aligned}
\left(-r+p u_{j}^{n}\right) u_{j+1}^{n+1} & +\left(2 r+1+p u_{j+1}^{n}-p u_{j-1}^{n}\right) u_{j}^{n+1} \\
& -\left(r+p u_{j}^{n}\right) u_{j-1}^{n+1} \\
& =r u_{j+1}^{n}+(1-2 r) u_{j}^{n}+r u_{j-1}^{n}
\end{aligned}
\end{aligned}
$$

We call the scheme (4) as Crank-Nicolson type method. We will prove that the scheme given in equation (3.2) is consistent and is of order two in space and time. The truncation error at $t=t_{n}$ and $x=x_{j}$ is given by

$$
\begin{aligned}
T_{j}^{n+1}=u_{t}+u u_{x} & -k u_{x x}-\frac{u\left(x_{j}, t_{n+1}\right)-u\left(x_{j}, t_{n}\right)}{\Delta t} \\
& -\frac{1}{4 \Delta x}\left\{u ( x _ { j } , t _ { n } ) \left[u\left(x_{j+1}, t_{n+1}\right)\right.\right. \\
& \left.-u\left(x_{j-1}, t_{n+1}\right)\right] \\
& \left.-u\left(x_{j}, t_{n+1}\right)\left[u\left(x_{j+1}, t_{n}\right)-u\left(x_{j-1}, t_{n}\right)\right]\right\}
\end{aligned}
$$

\begin{tabular}{|c|c|c|c|c|}
\hline \multicolumn{5}{|c|}{$T=0.01$} \\
\hline $\mathrm{x}$ & $\begin{array}{l}\text { Pandey et } \\
\text { al. }\end{array}$ & $\begin{array}{l}\text { Kadalbajoo et } \\
\text { al. }\end{array}$ & $\begin{array}{l}\text { Without Hopf } \\
\text { Cole }\end{array}$ & $\begin{array}{l}\text { Crank-Nicolson } \\
\text { Type Method }\end{array}$ \\
\hline 0.1 & 0.00016 & $6 \mathrm{E}-5$ & $5.78801 \mathrm{E}-5$ & $5.5967 \mathrm{E}-5$ \\
\hline 0.2 & 0.00031 & 0.00011 & 0.000109996 & 0.000106788 \\
\hline 0.3 & 0.00044 & 0.00016 & 0.000151182 & 0.000147685 \\
\hline 0.4 & 0.00051 & 0.00019 & 0.000177403 & 0.000174629 \\
\hline 0.5 & 0.00054 & 0.0002 & 0.000186149 & 0.000184737 \\
\hline 0.6 & 0.00051 & 0.00019 & 0.000176667 & 0.000176642 \\
\hline 0.7 & 0.00044 & 0.00016 & 0.000149991 & 0.000150777 \\
\hline 0.8 & 0.00031 & 0.00011 & 0.000108805 & 0.000109482 \\
\hline 0.9 & 0.00016 & $6 \mathrm{E}-5$ & 5.71442E-5 & $5.68618 \mathrm{E}-5$ \\
\hline
\end{tabular}

\begin{tabular}{|c|c|c|c|c|}
\hline $\mathrm{x}$ & $\begin{array}{l}\text { Pandey et } \\
\text { al. }\end{array}$ & $\begin{array}{l}\text { Kadalbajoo et } \\
\text { al. }\end{array}$ & $\begin{array}{l}\text { Without Hopf } \\
\text { Cole }\end{array}$ & $\begin{array}{l}\text { Crank-Nicolson } \\
\text { Type Method }\end{array}$ \\
\hline 0.1 & $7 E-5$ & $1 \mathrm{E}-5$ & $1.37807 \mathrm{E}-5$ & $1.33294 \mathrm{E}-5$ \\
\hline 0.2 & 0.00014 & $3 \mathrm{E}-5$ & $2.61869 \mathrm{E}-5$ & $2.54419 \mathrm{E}-5$ \\
\hline 0.3 & 0.00021 & $5 \mathrm{E}-5$ & $3.59876 \mathrm{E}-5$ & $3.52052 \mathrm{E}-5$ \\
\hline 0.4 & 0.00024 & $5 \mathrm{E}-5$ & $4.22225 \mathrm{E}-5$ & 4.16613E-5 \\
\hline 0.5 & 0.00025 & $6 \mathrm{E}-5$ & $4.42961 \mathrm{E}-5$ & 4.41193E-5 \\
\hline 0.6 & 0.00024 & $5 \mathrm{E}-5$ & 4.20319E-5 & $4.22449 \mathrm{E}-5$ \\
\hline 0.7 & 0.00021 & $5 \mathrm{E}-5$ & $3.56792 \mathrm{E}-5$ & $3.61289 \mathrm{E}-5$ \\
\hline 0.8 & 0.00014 & $3 \mathrm{E}-5$ & $2.58784 \mathrm{E}-5$ & $2.63157 \mathrm{E}-5$ \\
\hline 0.9 & $8 \mathrm{E}-5$ & $1 \mathrm{E}-5$ & 0.00001359 & 0.00001377 \\
\hline
\end{tabular}

$$
\begin{gathered}
+\frac{k}{2(\Delta x)^{2}}\left\{\left[u\left(x_{j+1}, t_{n+1}\right)-2 u\left(x_{j}, t_{n+1}\right)+u\left(x_{j-1}, t_{n+1}\right)\right]\right. \\
\left.-\left[u\left(x_{j+1}, t_{n}\right)-2 u\left(x_{j}, t_{n}\right)+u\left(x_{j-1}, t_{n}\right)\right]\right\}
\end{gathered}
$$

\begin{tabular}{|c|c|c|c|c|}
\hline $\mathrm{x}$ & $\begin{array}{l}\text { Pandey et } \\
\text { al. }\end{array}$ & $\begin{array}{l}\text { Kadalbajoo et } \\
\text { al. }\end{array}$ & $\begin{array}{l}\text { Without Hopf } \\
\text { Cole }\end{array}$ & $\begin{array}{l}\text { Crank-Nicolson } \\
\text { Type Method }\end{array}$ \\
\hline 0.1 & 0.00016 & $6 \mathrm{E}-5$ & $6.10384 \mathrm{E}-5$ & $4.44569 \mathrm{E}-5$ \\
\hline 0.2 & 0.00030 & 0.00011 & 0.0001156 & 0.00008722 \\
\hline 0.3 & 0.00042 & 0.00016 & 0.000157849 & 0.00012590 \\
\hline 0.4 & 0.00050 & 0.00018 & 0.00018329 & 0.00015688 \\
\hline 0.5 & 0.00054 & 0.0002 & 0.000189452 & 0.00017538 \\
\hline 0.6 & 0.00052 & 0.00019 & 0.000176365 & 0.00017622 \\
\hline 0.7 & 0.00045 & 0.00017 & 0.000146518 & 0.00015543 \\
\hline 0.8 & 0.00033 & 0.00048 & 0.000104112 & 0.00011242 \\
\hline 0.9 & 0.00018 & 0.00026 & $5.38605 \mathrm{E}-5$ & $5.159511 \mathrm{E}-5$ \\
\hline
\end{tabular}

Taylor's series expansion of above expression about $\left(x_{j}, t_{n}\right)$ gives

$$
T_{j}^{n+1}=\left(u_{t}-k u_{x x}+u u_{x}\right)_{t} \frac{\Delta t}{2}+o\left((\Delta t)^{2},(\Delta x)^{2}\right)
$$

Thus along (2.1) truncation error $T_{j}^{n+1}$ is of $o\left((\Delta t)^{2},(\Delta x)^{2}\right)$. The difference scheme is consistent for 1 dimensional nonlinear Burgers equation since the truncation error approaches zero as $\Delta t \rightarrow 0$ and $\Delta x \rightarrow 0$.

\section{NUMERICAL EXPERIMENTS AND ANALYSIS}

TABLE I: COMPARISON OF ABSOLUTE ERRORS [9], [27], [31] IN THE SOLUTION OF (1) FOR PROBLEM 1 WITH $K=10, \Delta t=0.0001$ AND $\Delta x=0.025$,

TABLE II: COMPARISON OF ABSOLUTE ERRORS [9], [27], [31] IN THE SOLUTION OF (1) FOR PROBLEM 1 WITH $K=10, \Delta t=0.0001$ AND $\Delta x=0.0125$, $T=0.01$

TABLE III: COMPARISON OF ABSOLUTE ERRORS [9], [27], [31] IN THE SOLUTION OF (1) FOR PROBLEM 1 WITH $K=1, \Delta t=0.001$ AND $\Delta x=0.025, T=0.1$

Numerical solutions of one dimensional nonlinear Burgers equation (1) are obtained by Crank-Nicolson Type method (4) for two problems given in section 1 and results are compared with existing three methods [9], [27], [31] and exact solution given in section 1. It is observed that the the method (4) gives more accurate solution than the other methods. Errors in the 
solution is compared with the errors in numerical solution obtained in [9], [27], [31]. Fig. 4 shows the comparison between analytic solution and numerical solution of (1) obtained by (4). The calculated absolute errors for different values of $t$ and constant of diffusivity $k$ are shown in Table I to Table VI. The graphs 1 to 6 of absolute errors are also given for comparison. In graph 7 and 8 we have calculated solutions at different values of $t$ and compared with exact solution.It is observed that the solution are compatible with the exact solution.

TABLE IV: COMPARISON OF ABSOLUTE ERRORS [9], [27], [31] IN THE SOLUTION OF (1) FOR PROBLEM 1 WITH $K=1, \Delta t=0.001$ AND $\Delta x=0.0125$, $T=0.1$

\begin{tabular}{|c|c|c|c|c|}
\hline $\mathrm{x}$ & $\begin{array}{l}\text { Pandey et } \\
\text { al. }\end{array}$ & $\begin{array}{l}\text { Kadalbajoo et } \\
\text { al. }\end{array}$ & $\begin{array}{l}\text { Without Hopf } \\
\text { Cole }\end{array}$ & $\begin{array}{l}\text { Crank-Nicolson } \\
\text { Type Method }\end{array}$ \\
\hline 0.1 & $7 E-5$ & $2 \mathrm{E}-5$ & $1.45914 \mathrm{E}-5$ & $1.06932 \mathrm{E}-5$ \\
\hline 0.2 & 0.00014 & $3 E-5$ & $2.76247 \mathrm{E}-5$ & $2.10603 \mathrm{E}-5$ \\
\hline 0.3 & 0.00020 & $4 \mathrm{E}-5$ & $3.76962 \mathrm{E}-5$ & $3.05840 \mathrm{E}-5$ \\
\hline 0.4 & 0.00023 & $4 \mathrm{E}-5$ & $4.37257 \mathrm{E}-5$ & $3.84221 \mathrm{E}-5$ \\
\hline 0.5 & 0.00025 & $5 \mathrm{E}-5$ & $4.51272 \mathrm{E}-5$ & 4.33974E-5 \\
\hline 0.6 & 0.00024 & $5 \mathrm{E}-5$ & $4.19278 \mathrm{E}-5$ & $4.41816 \mathrm{E}-5$ \\
\hline 0.7 & 0.00021 & $5 \mathrm{E}-5$ & $3.47543 \mathrm{E}-5$ & $3.96967 \mathrm{E}-5$ \\
\hline 0.8 & 0.00016 & $3 E-5$ & 0.000024642 & $2.96468 \mathrm{E}-5$ \\
\hline 0.9 & $8 \mathrm{E}-5$ & $2 \mathrm{E}-5$ & $1.27275 \mathrm{E}-5$ & 0.00001495 \\
\hline
\end{tabular}

TABLE V: COMPARISON OF ABSOLUTE ERRORS [9], [27], [31] IN THE SOLUTION OF (1) FOR PROBLEM 2 WITH $K=1, \Delta t=0.001$ AND $\Delta x=0.025, T=0.1$

\begin{tabular}{|c|c|c|c|c|}
\hline $\mathrm{x}$ & $\begin{array}{l}\text { Pandey et } \\
\text { al. }\end{array}$ & $\begin{array}{l}\text { Kadalbajoo et } \\
\text { al. }\end{array}$ & $\begin{array}{l}\text { Without Hopf } \\
\text { Cole }\end{array}$ & $\begin{array}{l}\text { Crank-Nicolson } \\
\text { Type Method }\end{array}$ \\
\hline 0.1 & 0.00012 & $6 \mathrm{E}-5$ & $6.34389 \mathrm{E}-5$ & $4.54183 \mathrm{E}-5$ \\
\hline 0.2 & 0.00023 & 0.00011 & 0.000119993 & 0.000089086 \\
\hline 0.3 & 0.00032 & 0.00016 & 0.000163549 & 0.000128584 \\
\hline 0.4 & 0.00037 & 0.00019 & 0.00018952 & 0.000160327 \\
\hline 0.5 & 0.00039 & 0.0002 & 0.000195514 & 0.000179487 \\
\hline 0.6 & 0.00038 & 0.0002 & 0.000181728 & 0.000180695 \\
\hline 0.7 & 0.00033 & 0.00017 & 0.000150809 & 0.000159687 \\
\hline 0.8 & 0.00024 & 0.00012 & 0.000107093 & 0.000115585 \\
\hline 0.9 & 0.00013 & $7 E-5$ & $5.53858 \mathrm{E}-5$ & $5.279539 \mathrm{E}-5$ \\
\hline
\end{tabular}

TABLE VI: COMPARISON OF ABSOLUTE ERRORS [9], [27], [31] IN THE SOLUTION OF (1) FOR PROBLEM 2 WITH $K=1, \Delta t=0.001$ AND $\Delta x=0.0125$,

\begin{tabular}{|c|c|c|c|c|}
\hline \multicolumn{5}{|c|}{$T=0.1$} \\
\hline $\mathrm{x}$ & $\begin{array}{l}\text { Pandey et } \\
\text { al. }\end{array}$ & $\begin{array}{l}\text { Kadalbajoo et } \\
\text { al. }\end{array}$ & $\begin{array}{l}\text { Without Hopf } \\
\text { Cole }\end{array}$ & $\begin{array}{l}\text { Crank-Nicolson } \\
\text { Type Method }\end{array}$ \\
\hline 0.1 & $3 \mathrm{E}-5$ & $1 \mathrm{E}-5$ & $1.51440 \mathrm{E}-5$ & $1.09217 \mathrm{E}-5$ \\
\hline 0.2 & $6 \mathrm{E}-5$ & $3 E-5$ & $2.86478 \mathrm{E}-5$ & $2.15248 \mathrm{E}-5$ \\
\hline 0.3 & $9 \mathrm{E}-5$ & $5 \mathrm{E}-5$ & $3.90448 \mathrm{E}-5$ & $3.12971 \mathrm{E}-5$ \\
\hline 0.4 & $9 E-5$ & $5 \mathrm{E}-5$ & $4.52233 \mathrm{E}-5$ & $3.93898 \mathrm{E}-5$ \\
\hline 0.5 & $1 \mathrm{E}-5$ & $5 \mathrm{E}-5$ & $4.65990 \mathrm{E}-5$ & 4.45943E-5 \\
\hline 0.6 & $1 E-5$ & $5 \mathrm{E}-5$ & $4.32271 \mathrm{E}-5$ & $4.55169 \mathrm{E}-5$ \\
\hline 0.7 & $9 \mathrm{E}-5$ & $5 \mathrm{E}-5$ & $3.57791 \mathrm{E}-5$ & 4.09940E-5 \\
\hline 0.8 & $6 \mathrm{E}-5$ & $3 E-5$ & $2.53375 \mathrm{E}-5$ & $3.06639 \mathrm{E}-5$ \\
\hline 0.9 & $3 E-5$ & $2 \mathrm{E}-5$ & $1.30758 \mathrm{E}-5$ & $1.54511 \mathrm{E}-5$ \\
\hline
\end{tabular}

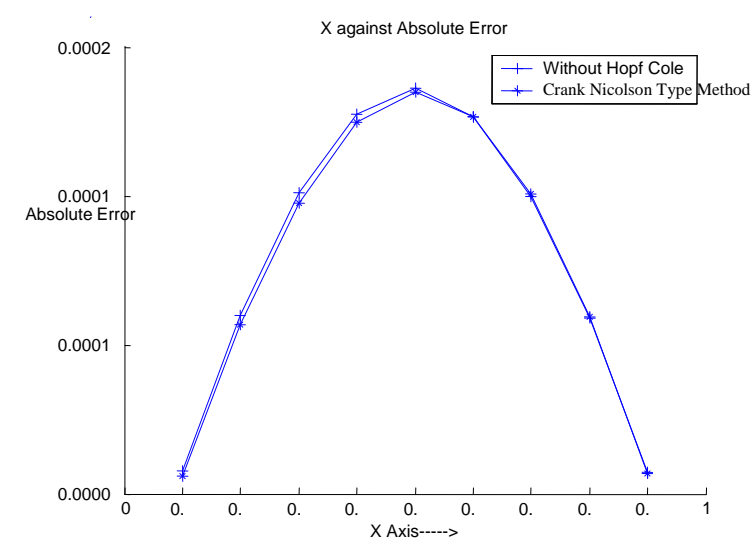

(a)

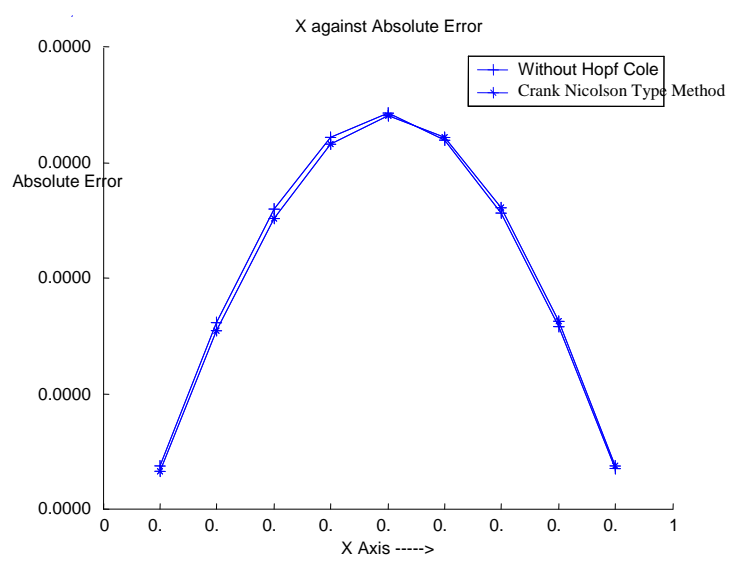

(b)

Fig. 1. Absolute errors for Problem 1 (a) $k=10, \Delta t=0.0001$ and $\Delta x=0.025$, $t=0.01$. (b) $k=10, \Delta t=0.0001$ and $\Delta x=0.0125, t=0.01$.

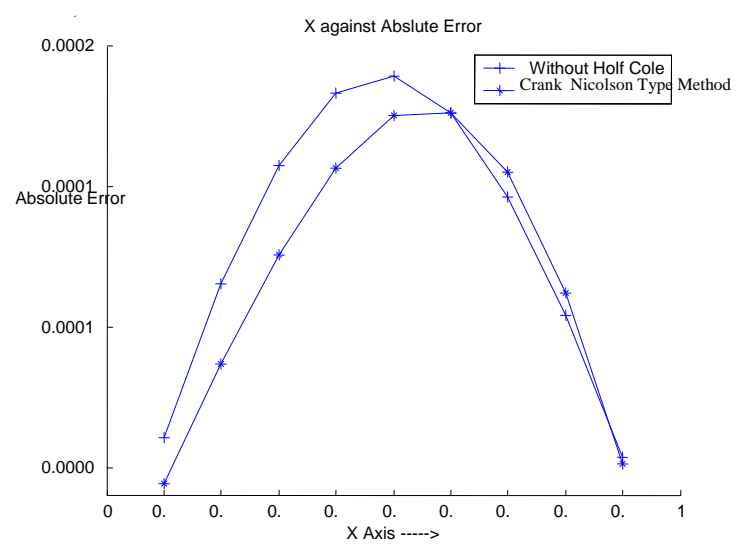

(a)

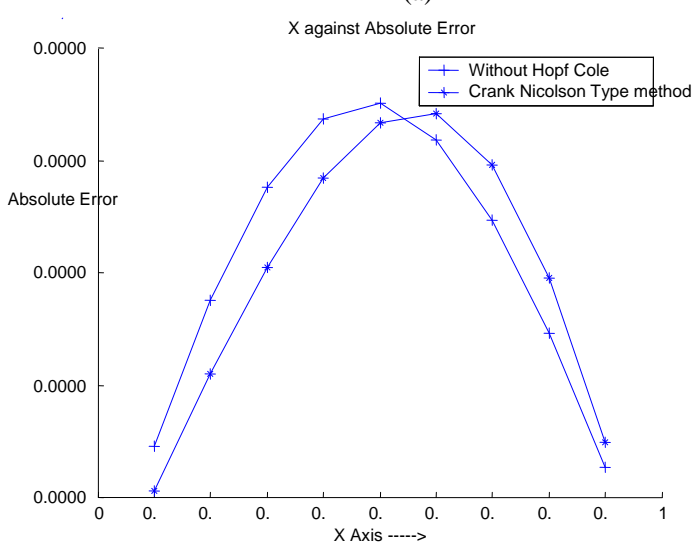

(b)

Fig. 2. Absolute errors for Problem 1 (a) $k=1, \Delta t=0.001$ and $\Delta x=0.025, t=0.1$. (b) $k=1, \Delta t=0.001$ and $\Delta x=0.0125, t=0.1$.

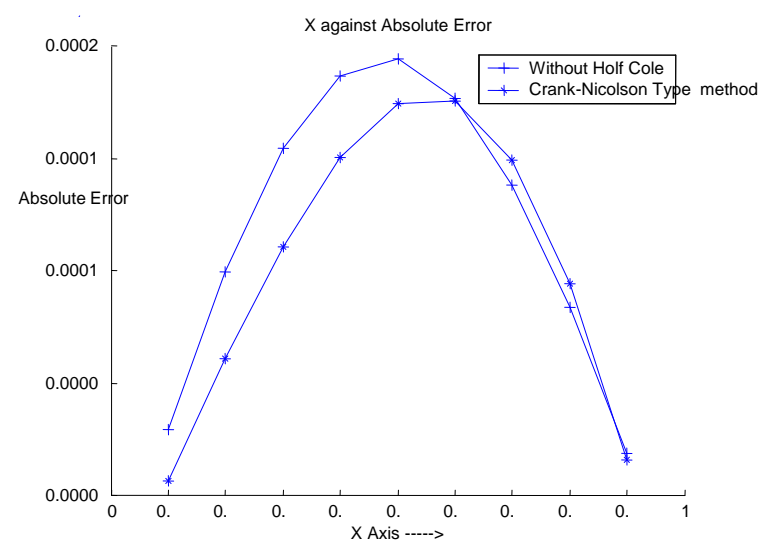

(a) 


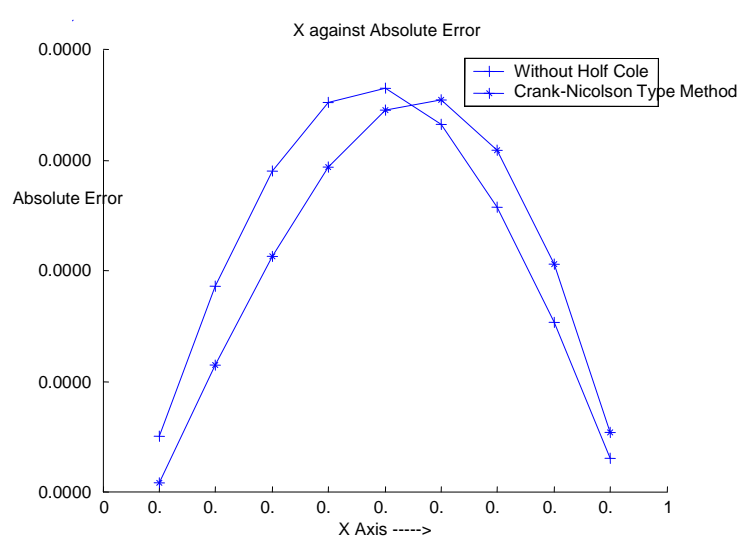

(b)

Fig. 3. Absolute errors for Problem 2 (a) $k=1, \Delta t=0.001$ and $\Delta x=0.025, t=0.1$. (b) $k=1, \Delta t=0.001$ and $\Delta x=0.0125, t=0.1$.

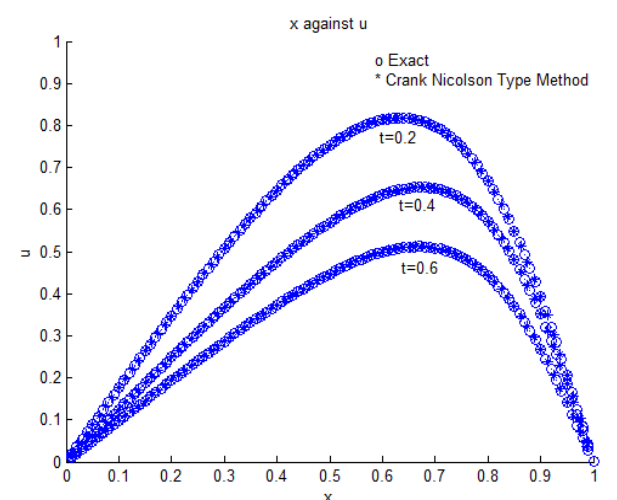

(a)

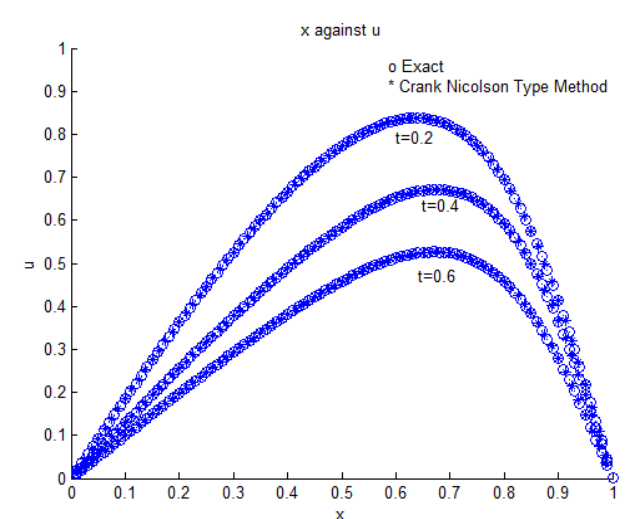

(b)

Fig. 4. Exact and Numerical Solution of Problem 1 (a) and 2 (b) with $k=0.1$, $\Delta t=0.001$ and $\Delta x=0.0125$ at different $t=0.2,0.4,0.6$.

\section{CONCLUSION}

A finite difference scheme called Crank-Nicolson type method is presented for numerical solution of one dimensional non linear Burgers Equation with Homogeneous Dirichelets boundary conditions. The method is proved to be consistent and is of order two in space and time. The numerical solution is calculated for two test problems with different values of constant of diffusivity $\mathrm{k}$. It is observed that the method is more accurate than the existing numerical methods [9], [27], [31].

\section{REFERENCES}

[1] H. Beteman, "Some recent researches on the motion of fluids," Mon. Weather Rev., vol. 43, 1915, pp. 163-170.
[2] J. M. Burger, "A Mathematical model illustrating the theory of turbulence," Adv. Appl. Mech, vol. 1, 1948, pp. 171-199.

[3] E. Hopf, "The partial differential equation $u_{t}+u u_{x}=\mu u_{x x}$.commun, pure," Appl. Math, vol. 3, 1950, pp. 301-330.

[4] J. D. Cole, "On a quasi linear parabolic equations occurring in aerodynamics," Quart. Appl. Math, vol. 9, 1951, pp. 225-236.

[5] B.-L. Kuo and C.-K. Chen "Application of a hybrid method to the solution of nonlinear Burgers equation," Journal of Applied mechanics, vol. 70, 2003, pp. 926-929.

[6] B. Saka et al., "A numerical solution of the Burgers equation using cubic B-splines," Applied Mathematics and computation, vol. 163, issue 5, April 2005, pp. 199-211

[7] M. K. Jain, "Numerical Solution of Differential Equations," New Age International $(P)$ Limited, New Delhi, 1984.

[8] N. J. Zabusky and M. D. Kruskal, "Interaction of Solitons in a Collisionless Plasma and the Recurrence of Initial States," Physical Review, vol. 15, no. 6, 1965, pp. 240-243, doi:10.1088/0305-4470/33/18/308.

[9] K. Pandey and L. Verma, "A Note on Crank Nicolson Scheme for Burgers Equation," Applied Mathematics, 2011, vol. 2, pp. 883-889.

[10] R. C. Mittal and P. Singhal, "Numerical solution of burgers equation," Commun. Numer. Math. Engg., 1993, pp. 397-406.

[11] S. Kutluay, A. R. Bahadir, and A. Ozdes, "Numerical solution of one dimensional Burgers equation: explicit and exact -explicit finite difference methods," J. Comput. Appl. math., vol. 103, 1999, pp. 251-261.

[12] T. Ozi, E. N. Aksan, and A. Ozdes, "A finite element approach for solution of Burgers equation," Appl. math. Comput, vol. 139, 2003, pp. 417-428.

[13] S. Kutluay, A. Esen, and I. DAg, "Numerical solution of the Burgers equation by the least squares quadratic B-spline finite element method," J. Compt. Appl. Math., vol. 167, 2004, pp. 21-33

[14] E. N. Aksan and A. Ozdes, "A numerical solution of Burgers equation," Appl. Math. Comput., vol. 156, 2004, pp. 395-402.

[15] I. A. Hassanient, A. A. Salama, H. H. Hosam, "Fourth order finite difference method for solving Burgers equation," Appl. Math. Comput., in press.

[16] N. Su, J. P. C. Watt, K. W. Vincent, M. E. Close, and R.Mao, "Analysis of Turbulent Flow Patterns of Soil Waterunder Field Conditions Using Burgers' Equation and PorousSuction-CupSamplers," Australian Journal of Soi Research, vol. 42, no. 1, 2004, pp. 9-16, doi:10.1071/SR02142

[17] P. F. Zhao and M. Z. Qin, "Multisymplectic Geometry and Multisymplectic Preissmann Scheme for the Kdv Equation," Journal of Physics A, vol. 33, no. 18, pp. 3613-3626, 2000.

[18] H. Brezis and F. Browder, "Partial Differential Equations in the 20th Century," Advances in Mathematics, vol. 135, no. 1, 1998, pp. 76-144, doi: 10 .1006/aima, 1997

[19] G. D. Smith, "Numerical Solutions of Partial Differential Equations", Oxford: Oxford University Press, 1978. Doi:10. 1016/j.amc. 2009. 08.018 .

[20] D. A. Anderson, J. C. Tannehill, and R. H. Pletcher, Computational Fluid mechanics and Heat transfer, Mc-Graw-HILL Book Company, 1984.

[21] S. S. Wani and S. Thakar, "Stability Analysis of Mixed Euler method for one dimensional nonlinear Burgers equation", Bulletin of Kerala Mathematical Association December 2009, vol. 5, no. 2, pp. 19-31.

[22] E. Benton and G. W. Platzman, "A table of solutions of the one dimensional Burgers equation," Quart Appl. Math, vol. 30, 1972, pp. 195-212.

[23] D. S. Zhang, G. W. Wei, and D. J. Kouri, "American Institute of Physics Fluids," Burgers equation with high Reynolds number, vol. 9, no. $6,1997$.

[24] A. Gorguis, "A Comparison between Cole-Hopf Transformation and Decomposition Method for Solving Burgers Equations," Applied Mathematics and Computation, vol. 173, no. 1, 2006, pp. 126-136.

[25] J. V. Lewandowski "Solution of Burgers equation using Marker method," International journal of numerical analysis and modeling, vol. 3, pp. 80-93

[26] K. Altiparmak "A Note on the Economized Rational Approximation method for solving," Burgers equation JFS, vol. 129, 2006.

[27] M. K. Kadalbajoo and A. Awasthi, "A Numerical Method Based on Crank-Nicolson Scheme for Burgers' Equation," Applied Mathematics and Computation, vol. 182, no. 2, 2006, pp. 1430-1442, doi:10.1016/j.amc.2006.05.030.

[28] J. Blazer and H. Aminikhah "Exact and Numerical solutions for non linear Burgers equation by VIM," Mathematical and Computing Modeling, vol. 49, issue 7-8, April 2009, pp. 1394-1400. 
[29] M. Basto, V. Semiao, and F. Calheiros "Numerical study of Modified Adomian's method applied to Burgers equation," Journal of Computational and Applied Mathematics, vol. 206, issue 2, 2007, pp. 927-949.

[30] J. K. Djoko "on the long time stability of a Backward Euler scheme for Burgers equation with polynomial force," Numerical methods for partial differential equation, vol. 24, issue 6, March 2008, pp. 1371-1387.

[31] K. Pandey, L.Verma, and A. K. Verma, "On a finite Difference Scheme for Burgers equation," Applied Mathematics and Computation, vol. 215 , no. 6,2009 .

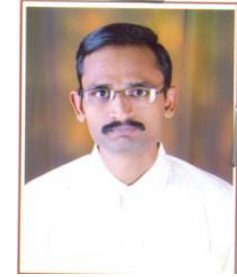

Sachin. S. Wani was born in Bhusawal, Maharashtra, India in 1980. He received the bachelor degree in mathematics in 2001 and master degree in computational mathematics from North Maharashtra University (NMU) in 2003, Jalgaon, India. Now he is an assistant professor at PIIT, India. $\mathrm{He}$ is $\mathrm{Ph} . \mathrm{D}$ student at Shivaji University Kolhapur, India. His main research interest is in numerical methods for PDE's.

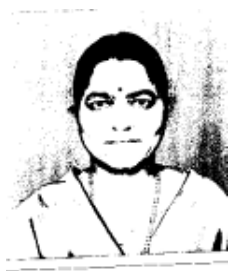

Sarita H. Thakar was born in Maharashtra, India. She received the master degree in 1987, M.phil degree in 1989 and Ph.D in 1993 from Pune University, India. Now she is a professor at Department of Mathematics, Shivaji University Kolhapur, India. Her main research interests are in numerical methods for PDE's, Fluid Dynamics and Classical Mechanics. 